\title{
Geociências
}

\section{O Graben de Apodi, região sudoeste da bacia Potiguar, RN, uma interpretação com base em seções sísmicas e dados de poços}

\section{(The Apodi graben, southwestern region of the Potiguar basin, $\mathrm{RN}$, an interpretation based on data obtained from seismic sections and wells)}

Marcus Roberto Hoerlle

Geofísico Sênior, PETROBRAS - Petróleo Brasileiro S.A., Rio de Janeiro, RJ - Email: hoerlle@petrobras.com.br

Caroline Janette Souza Gomes

Professora Associado I, Universidade Federal de Ouro Preto, Escola de Minas, Departamento de Geologia Programa de Pós-Graduação em Evolução Crustal e Recursos Naturais - E-mail: caroline@degeo.ufop.br

Renato Marcos Darros de Matos

Geofísico Sênior, Aurizônia Petróleo Ltda, Rio Grande do Norte, Natal -E-mail: renatodarros@aurizonia.com.br

\section{Resumo}

A evolução da bacia Potiguar, na Margem Equatorial Brasileira, apesar de constituir objeto de inúmeros estudos continua palco de controvérsias, em especial, no que diz respeito a sua extremidade sudoeste, o Graben de Apodi. Com o intuito de caracterizar a geometria da Falha de Apodi e entender o mecanismo de formação de dobras em suas adjacências, foram analisados seções sísmicas de reflexão e dados de poços. Confeccionaram-se mapas de contorno estrutural da Falha de Apodi e de isópacas da Formação Pendência, sin-tectônica. A análise das seções sísmicas revelou que variações na geometria da Falha de Apodi, que corresponde ao descolamento basal do graben homônimo, ocorrem vinculadas a modificações nas estruturas dos estratos sin-rifte. Os dados sugerem que o alto ângulo e flutuações de mergulho da Falha de Apodi causaram a formação de dobras de arrasto, bem como de sinformes e antiformes nos pacotes pré e sinrifte. Além disso, a distribuição dos depocentros da Formação Pendência, nas proximidades do descolamento basal e a noroeste do Alto de Quixaba, sugere para a Falha de Apodi forte componente normal e vários pulsos de atividade.

Palavras-chave: Bacia Potiguar, Graben de Apodi, Falha de Apodi, seções sísmicas de reflexão, descolamento basal, antiformes e sinformes.

\begin{abstract}
The origin and evolution of the Potiguar Basin have been a matter of discussion over the last two decades. Nevertheless, the tectonic evolution of the basin still remains controversial, in particular, its southern portion, the Apodi Graben. We used seismic reflection lines and well data to generate a set of isopach maps of the syn-rift Pendencia Formation, and a structural contour map of the Apodi Fault. The aim of this paper is to obtain a 3D structural picture of the Apodi Fault in order to interpret the associated Apodi Graben with special attention to the antiformal folds affecting the syn-rift section, previously interpreted as acommodation or oblique extensional/contractional structures. The geophysical and stratigraphic data sets suggest that: i) the Apodi Fault is a normal listric fault, with a local ramp-flat-ramp geometry; ii) thickness variations of depocenters, close to the Apodi Fault and to the northwest of the Quixaba High, reflect different pulses of fault activity during the Pendência Formation sedimentation; and iii) the $3 D$ variations in the Apodi Fault geometry represent the main cause of the occurrence of folds in the syn-rift sequence close to the master fault.
\end{abstract}

Keywords: Potiguar Basin, Apodi Graben, Apodi Fault, basal detachment geometry, antiformal and sinformal folds. 


\section{Introdução}

O objetivo do presente trabalho é reinterpretar a geometria da Falha de Apodi e a estruturação interna do graben homônimo, da porção sudoeste da bacia Potiguar, com base em 57 seções sísmicas de reflexão e de 12 poços. O trabalho é centrado na descrição da geometria tridimensional da Falha de Apodi e do comportamento do pacote sedimentar junto à mesma. Pretende-se analisar, em especial, as dobras presentes na Formação Pendência (sin-rifte), estruturas estas descritas como de encurtamento por Françolin e Szatmari (1987), de “acomodação" por Matos (1992) e de “transpressão/transtensão” por Borges (1993).

\section{Geologia regional}

A bacia Potiguar instala-se na Província Borborema, no extremo leste da Margem Equatorial Brasileira (Figura 1), e é controlada por zonas de cisalhamento preexistentes do embasamento (Almeida et al. 1977). O estudo dessa bacia, em virtude da sua situação geográfica, especial entre as bacias da margem leste e equatorial, desempenha um papel importante no entendimento da evolução geotectônica do Nordeste Brasileiro. Além disto, o seu preenchimento representa um registro estratigráfico quase completo do Cretáceo Inferior ao Terciário Superior.

\section{Estratigrafia}

Segundo Araripe e Feijó (1994), o pacote sedimentar da bacia Potiguar é constituído por três grandes grupos que da base para o topo são: Areia Branca, Apodi e Agulha. O Grupo Areia Branca representa, com as formações Pendência e Pescada, neocomanianas, a fase rifte da bacia. Trata-se de sedimentos de ambiente fluvial, respectivamente lacustre e deltaico e leques aluvionais. Ao final da fase rifte, a Formação Alagamar, aptiana, de características também fluviais, deltaico e lagunar, se depositou sobre uma discordância angular. Represen- ta a fase de transição da bacia para um ambiente marinho de margem passiva. As formações Açu, Ponta do Mel, Quebradas e Jandaíra, do Grupo Apodi, de idade albaniana a campaniana, constituem uma seqüência transgressiva que se inicia com sedimentos continentais clásticos, principalmente arenitos e pelitos, que gradam para sedimentos de plataforma rasa e carbonatos. A seqüência termina com os folhelhos e carbonatos da Formação Jandaíra, que afloram na bacia Potiguar, onshore. Na porção offshore da bacia, ocorrem ainda as formações Ubarana, Guamaré e Tibau do Grupo Agulha (campaniana a terciária), uma seqüência progradational composta por sedimentos siliciclásticos, carbonatos, folhelhos e turbiditos.

A Formação Pendência (objeto do presente estudo) é sobreposta discordantemente ao embasamento cristalino e sotoposta, também em discordância angular, à Formação Alagamar. É constituída por sedimentos de origem continental: conglomerados, arenitos e folhelhos aluvionares, flúvio deltaicos e lacustres preenchendo, preferencialmente, os baixos estruturais.

Della Fávera et al. (1992) propõem, para a Formação Pendência, quatro seqüências. Segundo os autores, as seqüências 1 e 2 representam fases deposicionais de lago profundo e as seqüências 3 e 4, sistemas deltaicos de lago raso.

\section{Arcabouço estrutural e modelos tectônicos}

O arcabouço tectônico da bacia Potiguar é caracterizado, a leste, pelo sistema de falhas Carnaubais-Baixa Grande, a oeste, pela Linha de Charneira de Areia Branca e, a sudoeste, pela Falha de Apodi (Figura 1). Em posição paralela ao Sistema Carnaubais - Baixa Grande, a oeste do Alto de Quixaba, ocorre um segundo sistema de falhas normais, que, às vezes, recebe a denominação de Falha de Quixaba. Para Matos (1992), os dois sistemas de falhas, enraizados no embasamento pré-cambriano, constituem um “descolamento duplo". Uma ex- tensão diferencial ao longo dessas falhas teria gerado os dois principais meiograbens da bacia Potiguar, de direção NESW: Umbuzeiro e Boa Vista.

O Graben de Apodi, no extremo sudoeste, se diferencia do restante da bacia pela presença de uma terceira grande falha normal, NE-SW (a Falha de Mulungu), esta, com caimento para sudeste, e que dá continuidade à Linha de Charneira de Areia Branca (Figura 1B). Além disto, observa-se, na região central e sudeste do graben, em planta, uma deflexão para noroeste do Alto de Quixaba e da Falha de Baixa Grande. O segmento NW-SE desta descontinuidade constitui a Falha de Apodi que, às vezes, é interpretada como uma falha de transferência.

Segundo Françolin e Szatmari (1987), a bacia Potiguar tem a sua gênese relacionada à separação dos continentes sul-americano e africano. Para esses autores, a separação se iniciou com uma rotação horária do continente sul-americano, em relação ao africano, gerando, na região nordeste brasileira, contração E-W e extensão N-S. Esse estado de tensão teria causado rifteamento, por extensão oblíqua dextral, ao longo de antigos lineamentos pré-cambrianos de direção NE-SW, assim como movimentos normais em falhas de orientação NW-SE, que delimitam a sua porção sul. Estruturas compressionais, tais como falhas reversas e dobras, reconhecidas na Formação Pendência do Graben de Apodi, estariam relacionadas a um encurtamento N-S, desencadeado durante o Cretáceo Superior.

Matos (1992) descreve o Graben de Apodi como parte de um meio-graben conjugado, cuja arquitetura interna estaria controlada pelo baixo ângulo de emergência de duas falhas normais. O processo de extensão teria evoluído em duas fases, com início no Neocomaniano Inferior quando um meio-graben simples teria se formado ao longo da Falha de Baixa Grande. Um segundo descolamento (a oeste do Alto de Quixaba) teria se tornado ativo em uma etapa tardia da 


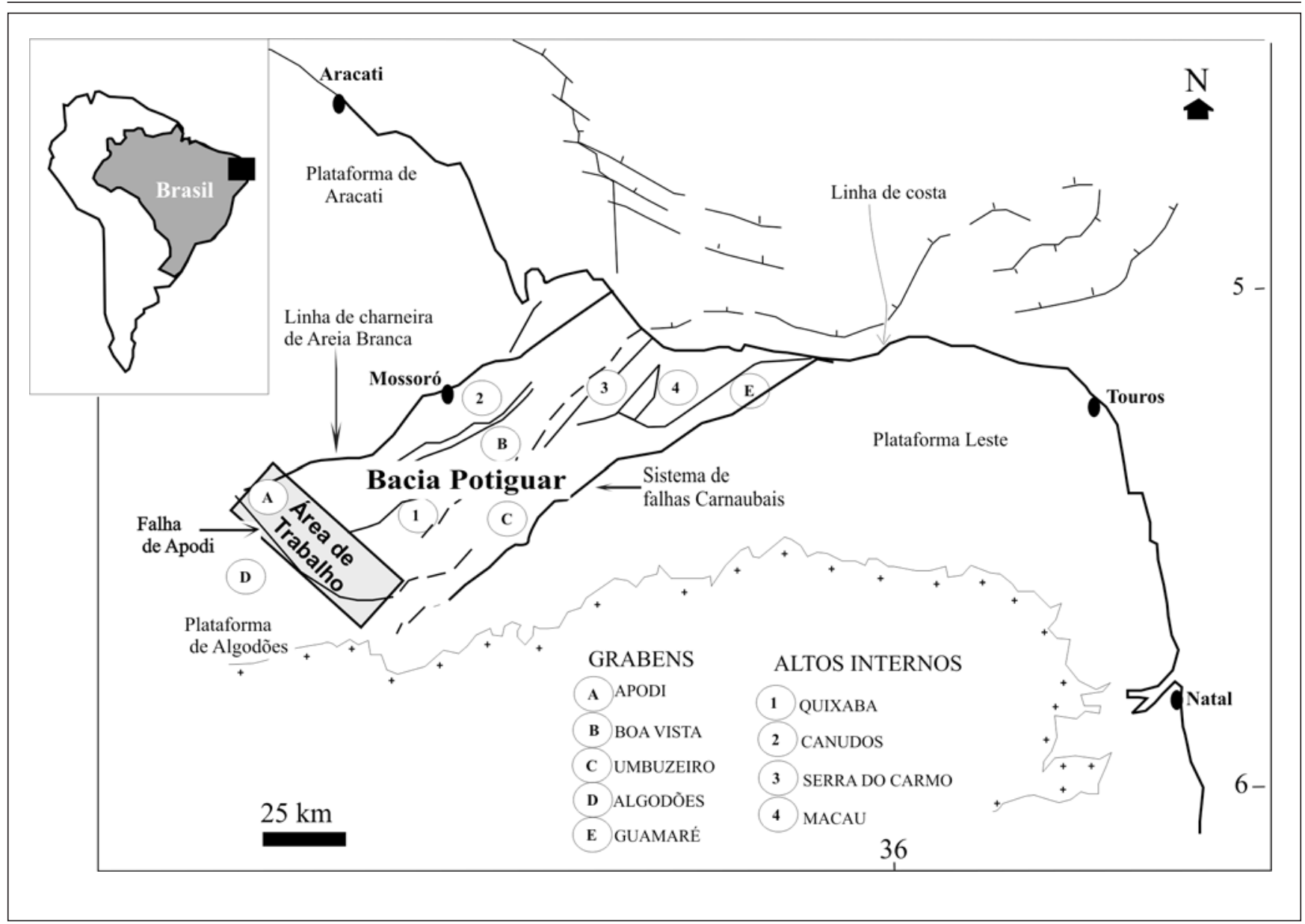

Figura 1 - (A) Arcabouço tectônico simplificado da bacia Potiguar (onshore) e sua localização geográfica. (B) Perfil NW-SE do Graben de Apodi (modificado de Matos 1992).

fase sin-rift, gerando outro meio-graben e uma estruturação descrita como cunha distensional, triangular, conceitualmente semelhante a uma zona triangular de cinturões compressivos. Nesse contexto, o segmento NW-SE, a Falha de Apodi, seria uma falha de transferência.

Para Borges (1993), que estudou a região sudoeste da bacia Potiguar, uma fase de inversão teria seguido a etapa distensional formadora da bacia. A inversão tectônica estaria associada a componentes contracionais, de direção NNW-SSE, em consequiência a um cisalhamento dextral de direção WNW, regional, relacionado ao início do rifteamento da Margem Equatorial. Para o autor, a inversão tectônica teria causado, no Graben de Apodi, um encurtamento no seu domínio sudeste com formação de estruturas positivas, transpressivas e transtrativas.

\section{Metodologia de trabalho}

Entre as 57 seções sísmicas de reflexão analisadas, selecionaram-se, para a descrição, seis linhas, com ênfase na região central do Graben de Apodi (Figura 2). Reproduzidas nas Figuras 3 e 4, todas essas seções são apresentadas em tempo duplo.

Os dados dos 12 poços foram empregados para a confecção de um mapa de contorno estrutural do plano da Falha de Apodi (Figura 2) e de mapas de isópacas das 4 seqüências da Formação Pendência (Figura 5). Informações de poços incompletos, que não atingiram todas as seqüências, foram complementadas com interpretações das linhas sísmicas. Nessas situações, para a transformação dos dados em tempo, para pro- fundidade, usou-se o perfil sônico dos poços ou a velocidade intervalar das linhas sísmicas.

\section{Resultados Interpretação sísmica}

A comparação entre todas as linhas sísmicas (Figuras 3 e 4 ) revela que, com exceção da linha L1, a Falha de Apodi se horizontaliza em torno de 3 segundos. Tal profundidade, em metros, corresponde ao intervalo de 5.000 a 5.500 m. Além disto, o mapa de contorno estrutural mostra que o ângulo de mergulho da Falha de Apodi varia. É mais suave nas linhas L7, L4 e L3, mais elevado em L2, e intermediário, nas seções L1 e L5.

Nas seções sísmicas da Figura 3 (L1, L2 e L4), o bloco do teto da falha 
O Graben de Apodi, região sudoeste da bacia Potiguar, RN, uma interpretação com base em ...

mestra, de geometria em roll-over, é sempre seccionado por falhas normais secundárias. Destaca-se a forma do bloco do teto levemente côncava no perfil L2, que destoa da geometria convexa normal. Nas linhas L1 e L4, o anticlinal de roll-over é convexo, havendo variações na curvatura.

Na seção sísmica L1 (Figura 3A), de direção NNW-SSE, observam-se, além da falha mestra, duas falhas sintéticas. Todas as falhas apresentam a mesma geometria lístrica e ângulo de mergulho similar. Na parte média do Graben de Apodi, o pequeno alto observado coincide, em planta, com a posição do Alto de Quixaba.

Nas linhas L2 e L4 (Figuras 3B e C), de direção WNW-ESE e NNW/SSE, respectivamente, o bloco do teto da falha mestra (embasamento pré-rifte) possui geometria de anticlinal de roll-over mais pronunciada do que aquela da seção L1. $\mathrm{O}$ anticlinal de roll-over, que aqui tam- bém constitui o Alto de Quixaba, é cortado por falhas normais sintéticas e antitéticas. A linha L2 se destaca, entre as três linhas da Figura 3, pelo maior rejeito da falha normal sintética (oeste), e a seção L4, pelo menor deslocamento. Os sedimentos sin-rifte mostram, na linha L1, sobre a falha normal sintética, um pequeno rejeito normal, caracterizando uma flexão monoclinal. É interessante notar que a magnitude do movimento dos sedimentos não corresponde à magnitude do rejeito da falha. Esse fato sugere que ocorreu a formação de um crestal-collapse graben, sobre o anticlinal de roll-over, com preenchimento sedimentar sintectônico, seguindo-se uma reativação da falha sintética. Na linha L4, o baixo rejeito das falhas secundárias e a configuração do pacote sedimentar, sin-rifte, plano-paralelo, sobre o anticlinal de rollover, balizam a hipótese da formação de um crestal-collapse graben, no caso, preservado de reativação.
A linha sísmica L2 (Figura 3) apresenta, nas adjacências da Falha de Apodi, na Formação Pendência, uma ampla estrutura em sinforme. Uma análise cuidadosa dessa flexão sugere, para a dobra, formação por arrasto ao longo do descolamento basal de alto ângulo de mergulho. Na linha L4, ocorre, além do sinforme, um antiforme, este associado a uma falha antitética e a um pequeno patamar na falha mestra.

Nenhuma das linhas L3, L5 e L7 (Figura 4), mostra falhas normais seccionando o bloco do teto (o Alto de Quixaba) da Falha de Apodi. Este fato é notável, especialmente porque a seção L3 se situa a sudeste da linha L4 e esta ainda é caracterizada por um sistema de falhas normais secundárias. Considerando-se, na linha L4, o baixo rejeito dessas falhas, é possível que o crestal-collapse graben termine na região das seções L2, L3 e L4 e que essa terminação seja caracterizada por um conjunto de segmentos descontínuos.

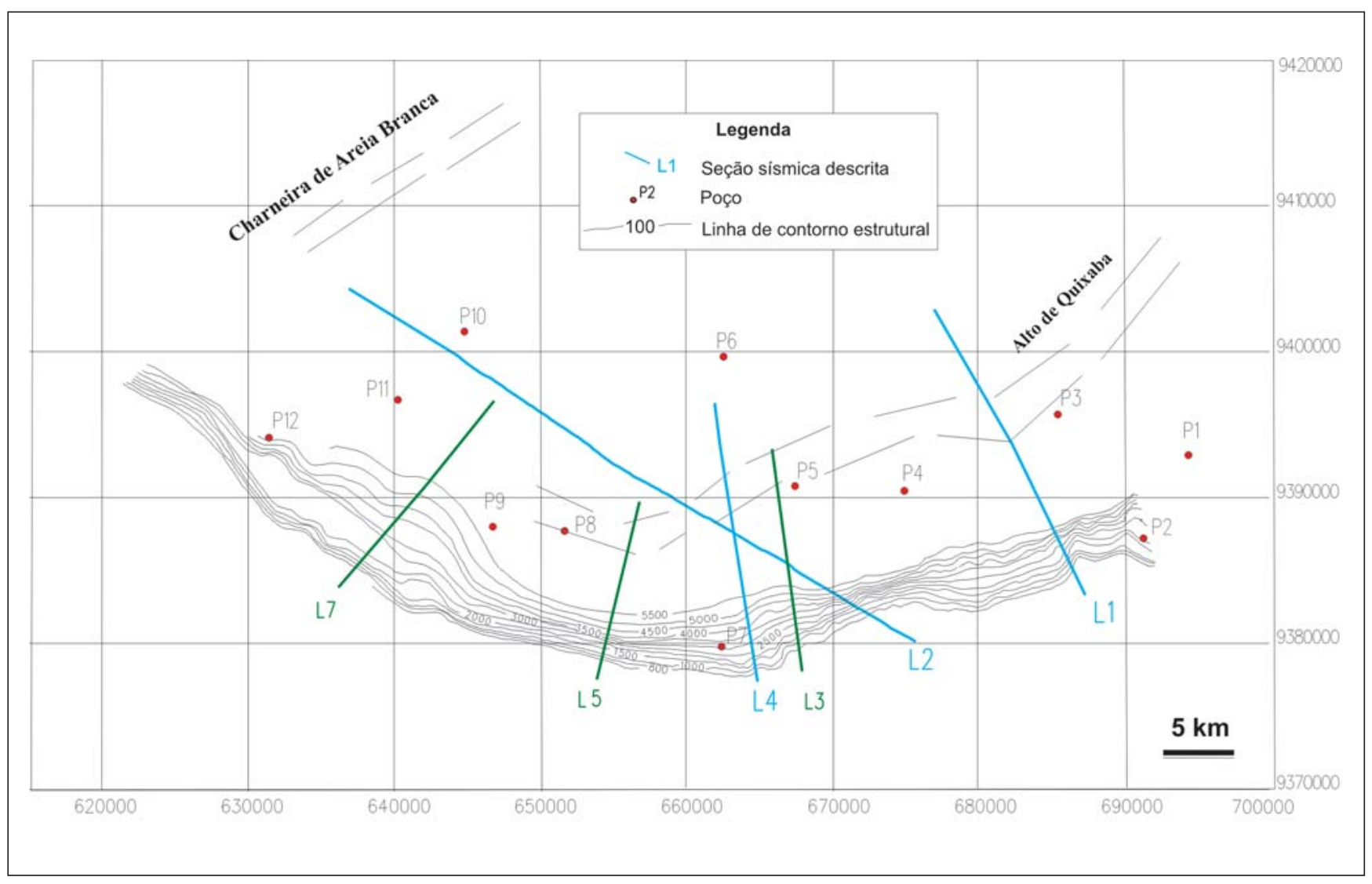

Figura 2 - Localização das seções sísmicas e dos poços estudados no mapa de contorno estrutural do plano da Falha de Apodi. Intervalos de contornos em metros. As linhas em azul mostram as seções sísmicas da Figura 3 e as em verde, aquelas da Figura 4. 


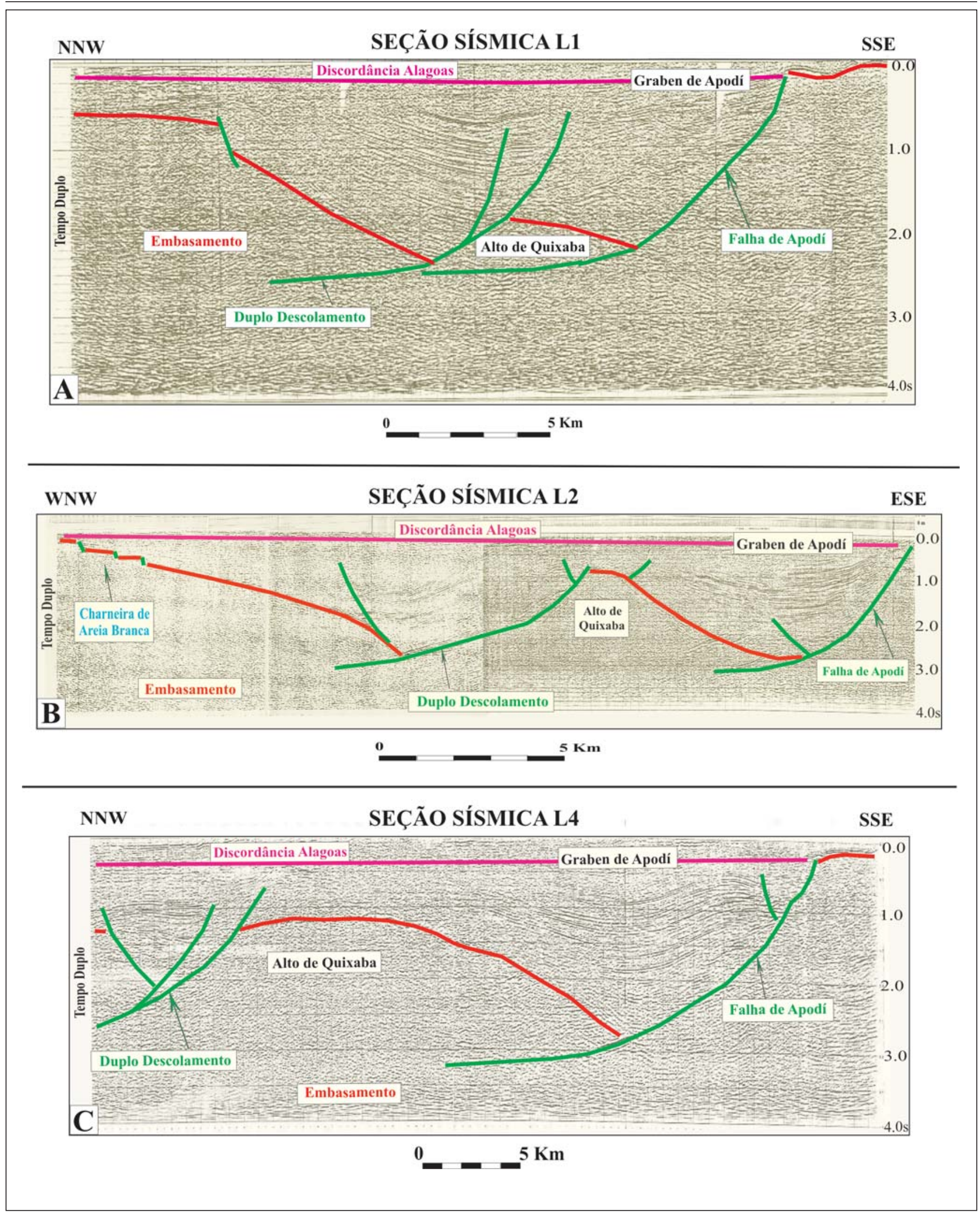

Figura 3 - Seções sísmicas (em tempo) interpretadas do domínio sudeste da Falha de Apodi. (A) Seção sísmica L1; (B) Seção sísmica L2; (C) Seção sísmica L4. Em todas as seções, o embasamento cristalino é representado por traços vermelhos; as falhas por traços verdes e a Discordância Alagoas, por um traço na cor roxa. 


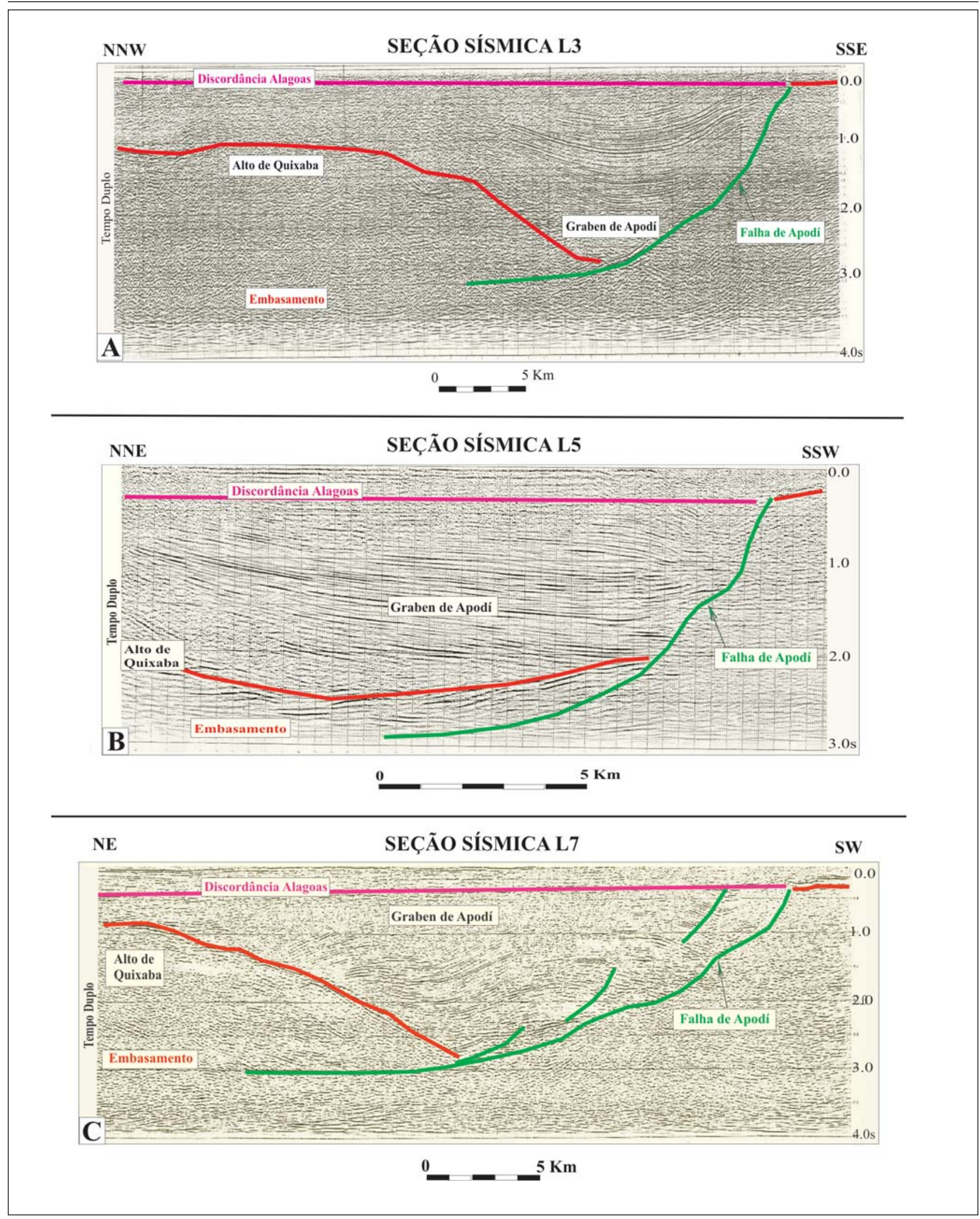

Figura 4 - Seções sísmicas (em tempo) interpretadas do domínio central e noroeste da Falha de Apodi. (A) Seção sísmica L3; (B) Seção sísmica L5; (C) Seção sísmica L7. Em todas as seções, o embasamento cristalino é representado por traços vermelhos; as falhas por traços verdes e a Discordância Alagoas, por um traço na cor roxa. 
Entre as três linhas sísmicas da figura 4, destaca-se a seção L5 (Figura 4B) pela curvatura côncava, peculiar, do bloco do teto do descolamento. Além disto, nota-se, nessa linha, que os estratos sedimentares do Graben de Apodí possuem, próximo à falha, uma configuração inusitada. Observam-se camadas com arrasto reverso sobre outras com arrasto normal. Os fatos sugerem que a geometria da superfície da falha, lístrica, de alto ângulo de mergulho, tenha causado arrasto no bloco do embasamento e que a morfologia irregular, tenha influenciado o caráter do deslocamento dos estratos.

A superfície da Falha de Apodi, na linha L3 (Figura 4A), revela a presença de irregularidades sutis. Estas crescem de tamanho nas seções sísmicas posicionadas no setor noroeste da Falha de Apodi. Passam a pequenos patamares suborizontais, na seção L5 (Figura 4B), e a uma geometria de rampa-patamar na linha L7 (Figura 4C).

Da mesma forma que a linha L4 (Figura 3C), a seção L3 (Figura 4A) mostra os estratos sin-rifte, com geometria sinformal e antiformal. Estruturas em antiforme e sinforme aparecem novamente na linha L7 (Figura 4C). Nessa linha, no entanto, observa-se que a posição do antiforme variou, o que sugere que exista uma relação dessas dobras com a morfologia da superfície da falha e com a presença de falhas secundárias.

\section{Mapas de isópacas da Formação Pendência}

Os mapas de isópacas da Formação Pendência (Figura 5) apresentam um grande número de depocentros. A maioria ocorre próximo à Falha de Apodi. Outros, entretanto, relativos às seqüências 3 e 4, são observados a noroeste do Alto de Quixaba.

A Seqüência 1 (Figura 5A), que possui a menor espessura das quatro unidades, forma depocentros de $400 \mathrm{~m}$ próximo à borda do Graben de Apodi. Outros, menores, de 200 m, são registrados na região central e norte. A maior espessura de sedimentos, de $1800 \mathrm{~m}$, foi registrada na Seqüência 2 (Figura 5B), no poço P9, junto a Falha de Apodi. Trata-se de um depocentro alongado, paralelo à falha, com afinamentos em direção aos altos internos. O mapa de isópacas da Seqüência 3 (Figura 5C) apresenta a sedimentação mais uniforme de todas as seqüências. A sua maior espessura (1400m) foi encontrada no poço P2 junto à Falha de Baixa Grande. Porém verificase a presença de outros depocentros de 1.200 m e 800 m, junta à Falha de Apodi e ao Alto de Quixaba, respectivamente. As maiores espessuras preservadas da $\mathrm{Se}$ qüência 4 (1.545 m) (Figura 5D) encontram-se na porção oeste do Graben de Apodi, junto ao poço P11.

O espessamento do pacote sedimentar junto à Falha de Apodí sugere tratar-se de uma falha com forte componente normal, ativa durante toda a fase rifte. A distribuição e o número de depocentros da Formação Pendência apontam, além disto, para a atividade da Falha de Apodi em diferentes pulsos.

\section{Mapa de contorno estrutural da Falha de Apodi}

A feição mais marcante da Falha de Apodi no mapa de contorno estrutural (Figura 2) é a distribuição heterogênea das curvas de contorno estrutural. As concentrações maiores, na região das linhas L5 e L2, confirmam o alto ângulo de mergulho descrito para o plano da falha a partir das seções sísmicas; as menores, o baixo ângulo, nas linhas sísmicas L4, L3e L7.

As linhas de contorno estrutural, no domínio noroeste, mostram padrão diferente do restante da área. Nesse domínio, as curvas de 3.000 m e 3.500 m apresentam espaçamento anormalmente elevado. Essa feição confirma a trajetória em degrau da falha, como já interpretado na linha sísmica L7 (Figura 4C).

\section{Discussão e conclusão}

A descrição das seções sísmicas e dos dados de poços do Graben de Apo- di revelou uma variação na geometria do plano da Falha de Apodi, em 2 e 3D. Além disto, demonstrou que as mudanças na morfologia da superfície da falha são acompanhadas por modificações no comportamento dos estratos sin-rift. Assim, existem domínios caracterizados por uma única flexão, sinformal, outros por antiformes e sinformes e um terceiro, mostrando apenas arrastos reverso e normal.

A distribuição e o número de depocentros da Formação Pendência, no Graben de Apodi, sugerem para a Falha de Apodi caráter distensivo, marcado por diferentes pulsos de atividade. As seções sísmicas indicam para o plano da falha uma geometria lístrica e mostram que o bloco do teto é representado pelo Alto de Quixaba. A superfície muda ao longo de sua extensão de lístrica simples, na região sudeste, para uma geometria de rampa-patamar-rampa, no sentido noroeste. As seções permitiram observar que o patamar nasce na região central do graben, onde é caracterizado, inicialmente, como uma pequena irregularidade na trajetória curva da falha. Além disto, são reconhecidas falhas secundárias no bloco do teto da Falha de Apodi, no sentido sudeste. Essas falhas sugerem a presença de um crestal-collapse graben e, nesse contexto, é possível relacionar a principal falha sintética à de maior rejeito normal, ao "segundo descolamento” descrito por Matos (1992).

O mapa de contorno estrutural e as seções sísmicas mostram dois domínios da Falha de Apodi de mergulho elevado (as regiões cortadas pelas linhas L2 e L5). Esses domínios coincidem com uma geometria levemente côncava do bloco do teto (embasamento), ao invés de convexo, normalmente descrito para sistemas de falhas lístricas. Uma estrutura sinformal, junto à Falha de Apodi, é descrita no pacote sin-rifte da linha L2 (Figura 3B) e aponta, da mesma forma que a geometria côncava do bloco do teto, para um arrasto normal.

Em experimentos analógicos de areia é comum observar um arrasto de pré- e sin-rifte nas adjacências do des- 


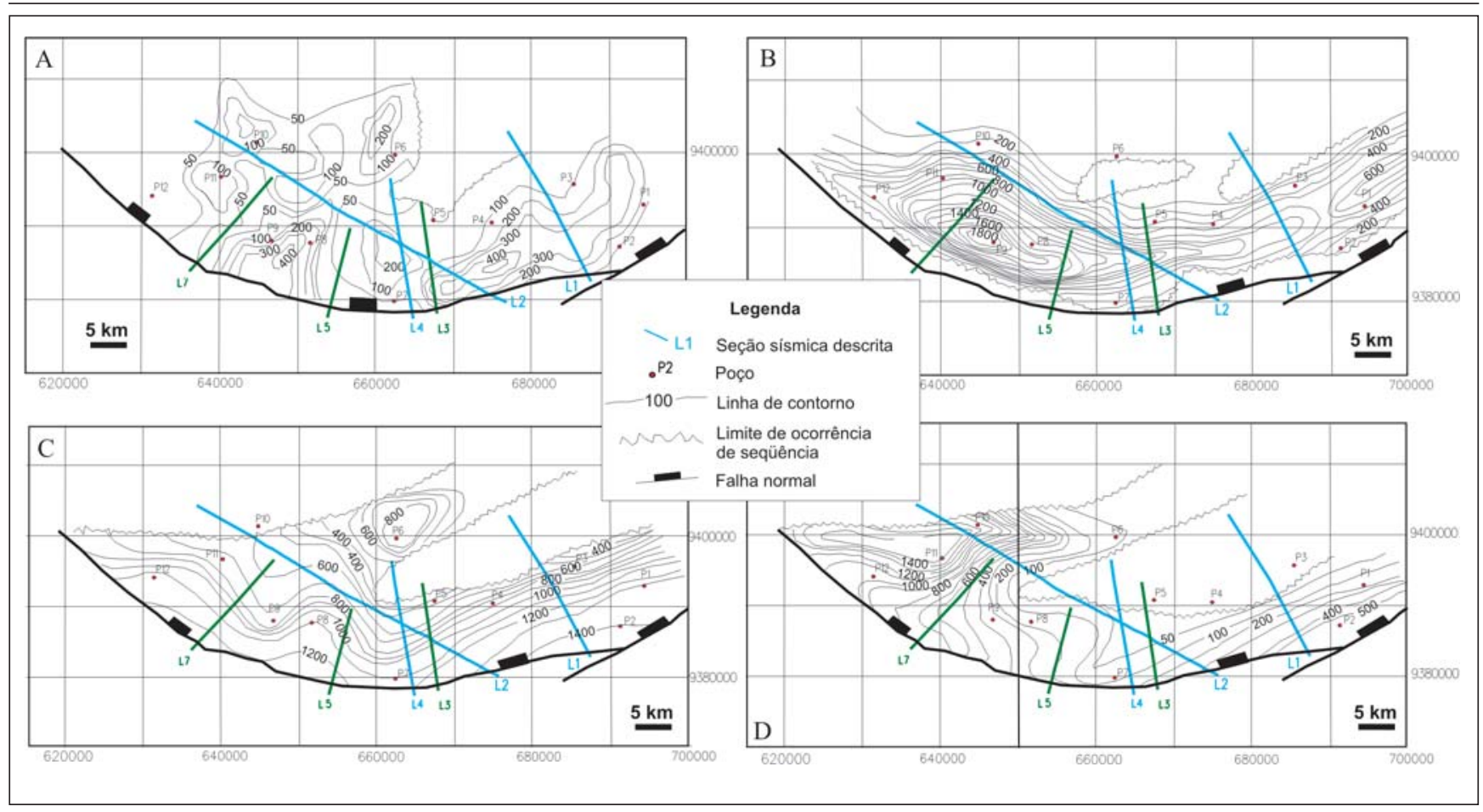

Figura 5 - Mapas de isópacas da Formação Pendência, no Graben de Apodi, com a localização das seções sísmicas utilizadas em presente trabalho e os poços da região. (A) Seqüência 1; (B) Seqüência 2; (C) Seqüência 3; (D) Seqüência 4 . Intervalos de contornos em metros.

colamento basal de hemi-grabens. A Figura 6 ilustra esse arrasto, em um modelo distensivo, que, no caso, reflete um alto coeficiente de atrito basal da falha mestra.

A formação de estruturas antiformais, em ambientes distensivos, não é comum. Existem, no entanto, registros, na literatura, como, por exemplo, o de Brumbaugh (1984), da região central e sul do Arizona (E.U.A). Modelos analógicos desenvolvidos por McClay e Scott (1991) também revelam que patamares curtos ou pequenas perturbações na geometria lístrica de um descolamento normal podem gerar falhas secundárias reversas em regime extensional e, associadas a estas, dobras antiformais (Figura 7). Apesar da ausência de falhas comprovadamente reversas nas linhas L4, L3 e L7, as feições descritas, a geometria heterogênea da Falha de Apodi, com o segundo patamar se iniciando como uma pequena irregularidade, e as falhas secundárias sintéticas e antitéticas junto à falha mestra permitem propor para as dobras antiformais origem por compres- são local, à semelhança do que ocorreu no modelo experimental anteriormente citado. Sugere-se, ainda, que as freqüentes intercalações de folhelho, nos pacotes de areia, da Formação Pendências, tenham induzido a um intenso deslizamento entre as camadas causando a estruturação bem definida das dobras sinformais e antiformais.

O procedimento de balizar hipóteses por meio de modelos experimentais é comum no estudo da tectônica de bacias sedimentares. No presente caso, as interpretações se basearam em simulações da literatura de falhas mestras com morfologia homogênea, embora este não seja o caso da falha estudada. Uma pesquisa de modelagem experimental, envolvendo a relação entre a geometria tridimensional, variável, do descolamento basal, e as estruturas resultantes, merece ser desenvolvida com maiores detalhes. Apesar disto, o conjunto de dados permite sugerir que as dobras da Formação Pendência do Graben de Apodi sejam de origem sintectônica.
Os movimentos normais ao longo da Falha de Apodi sugerem uma extensão regional N-S tal como preconizado por Françolin e Szatmari (1987), para a formação da bacia Potiguar. Apesar de discordar na direção da abertura da bacia, o presente estudo confirma o modelo de Matos (1992) para o Graben de Apodi, de meio-graben conjugado associado a um sistema de "descolamento duplo". Nesse contexto sugere-se que a Falha de Apodi constitua o descolamento basal do Graben de Apodi com características de falha normal de geometria variável, em 2 e 3 D, e que o "segundo descolamento" (a Falha de Quixaba) termine nas proximidades desta.

\section{Agradecimentos}

À Petróleo Brasileiro S.A., por conceder o material de estudo do presente trabalho. À Universidade Federal de Ouro Preto, permitindo o uso e acesso de seus laboratórios, equipamentos, materiais, e pela orientação no presente trabalho. 
Marcus Roberto Hoerlle et al.
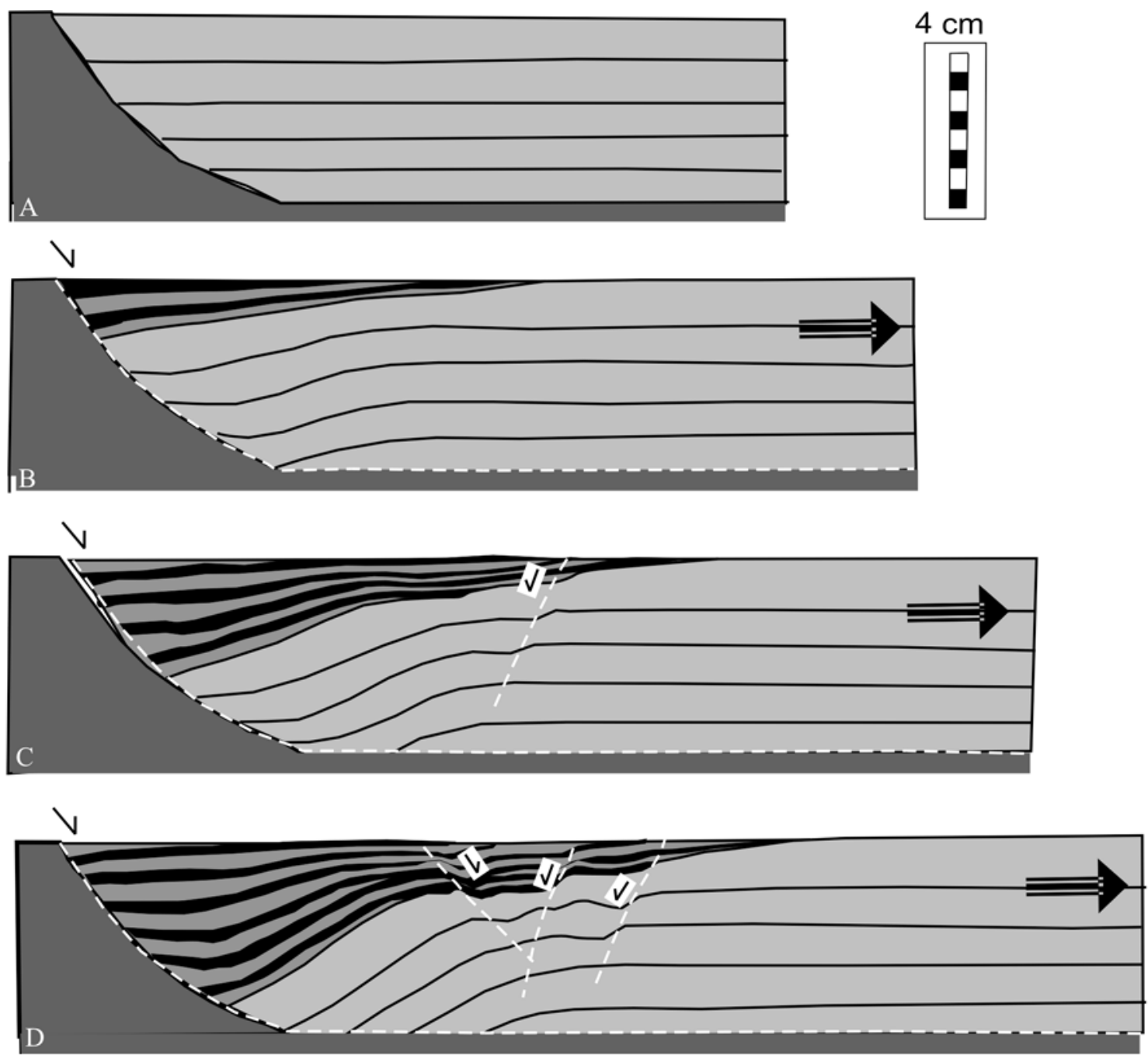

Figura 6 - Desenhos de fotografias de um modelo de areia simulando uma extensão progressiva: (A) antes, (B) após $2 \mathrm{~cm}(14,3 \%)$, (C) após $4 \mathrm{~cm}(28,6 \%)$ e (D) após $6 \mathrm{~cm}(42,9 \%)$ de extensão. Observar o arrasto das camadas junto à falha normal lístrica. A seta indica o sentido do movimento. O pacote de camadas cinza e preto, mais escuro, simula o depósito sin-rifte; o mais claro, o pré-rifte (mod. de Gomes et al. submetido).

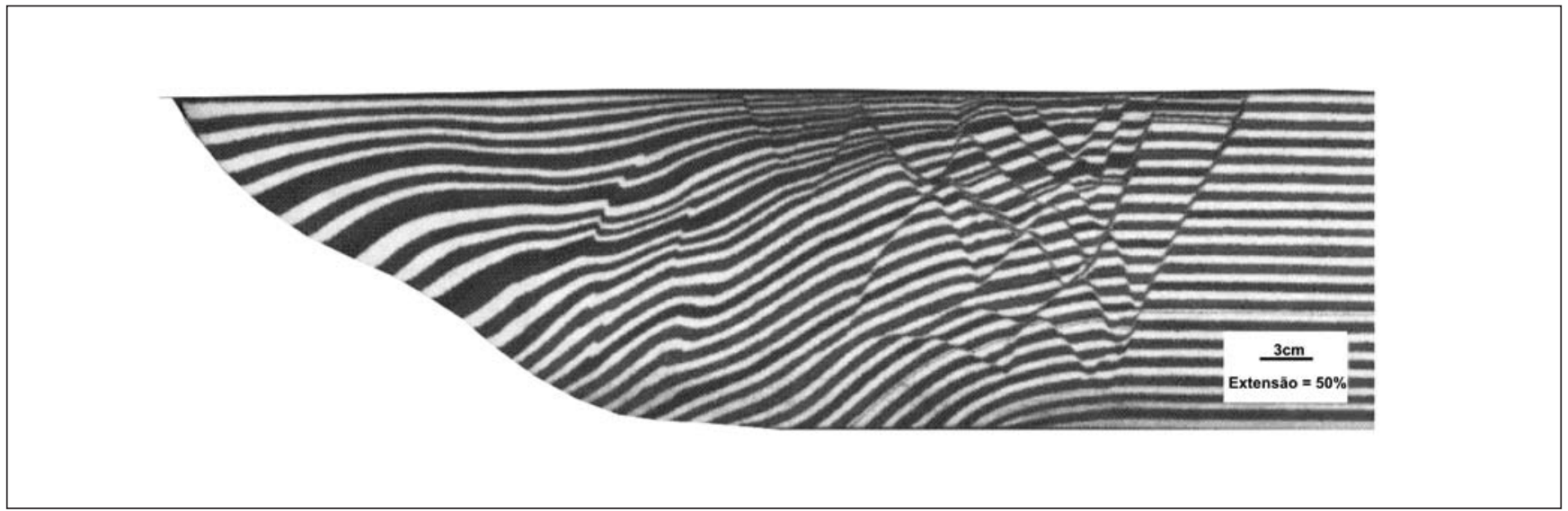

Figura 7 - Experimento simulando a deformação ao longo de uma falha normal lístrica com pequena perturbação na sua trajetória. Notar as falhas reversas e um antiforme junto ao descolamento basal (mod. de McClay \& Scott 1991). 
O Graben de Apodi, região sudoeste da bacia Potiguar, RN, uma interpretação com base em ...

7. Referências

\section{bibliográficas}

ALMEIDA, F.F.M., HASUI, Y., NEVES, B.B.B., FUCK, R.A. Províncias estruturais brasileiras. In: SIMP. GEOL. NORDESTE, 8. Anais... Campina Grande: SBG-NE, 1977, Bol. 6, p. 363391, 1977.

ARARIPE, P.T., FEIJÓ, F.J. Carta estratigráfica da bacia Potiguar. Boletim de Geociências da Petrobras, v. 8, n. 1, p. 127-141, 1994.

BERTANI, R.T., COSTA, I.G., MATOS, R.M.D. Evolução tectono-sedimentar, estilo estrutural e habitat do petróleo na Bacia Potiguar. In: ORIGEM E EVOLUÇÃO DE BACIAS SEDIMENTARES. RAJA GABAGLIA,
G.P., MILANI, E.J. (coords.). Rio de Janeiro: 1990. p. 291-310.

BORGES, W.R.E. Caracterização estrutural da porção sudoeste do Rift Potiguar, Brasil. Ouro Preto: Universidade Federal de Ouro Preto, 1993. 146p. (Dissertação de mestrado).

BRUMBAUGH, D.S. Compressive strains generated by normal faulting. Geology, v.12, p. 491-494, 1984.

DELLA FÁVERA, J.C., ROSSETTII, E.L., GUZZO, J., MATSUDA, N., SOARES, U.M., HASHIMOTO, A.T., ALVES, D.B., CASTRO, J.C., AZAMBUJA, N.C., RODRIGUES, R. Estratigrafia de seqüências da formação pendência, bacia Potiguar. Petrobras/DepexCenpes. Relatório Interno, 1992. 46 p.

FRANÇOLIN, J.B.L., SZATMARI, P. Mecanismo de rifteamento da porção oriental da margem norte brasileira. Revista Brasileira de Geociências, v. 17, p.196-207, 1987.

GOMES, C.J.S., DANDERFER, A., ABAD-POSADA, A.M., SILVA, A. C. The role of backstop shape during inversion tectonics - physical models. Anais da Academia Brasileira de Ciências (submetido).

MATOS, R.M.D. Deep seismic profiling, basin geometry and tectonic evolution of intracontinental rift basins in Brazil. U.S.A.: Cornel University, 1992. 276p. (Ph.D. Dissertation).

McCLAY, K.R., SCOTT, A.D. Experimental models of hangingwall deformation in ramp-flat listric extensional fault systems. Tectonophysics, v.188, p. 85-96, 1991.

Artigo recebido em 21/12/2006 e aprovado em 22/06/2007.

\section{Descubra as muitas informações da:}

\section{Geologia, Mineração, Metalurgia \& Materiais} e Engenharia Civil.
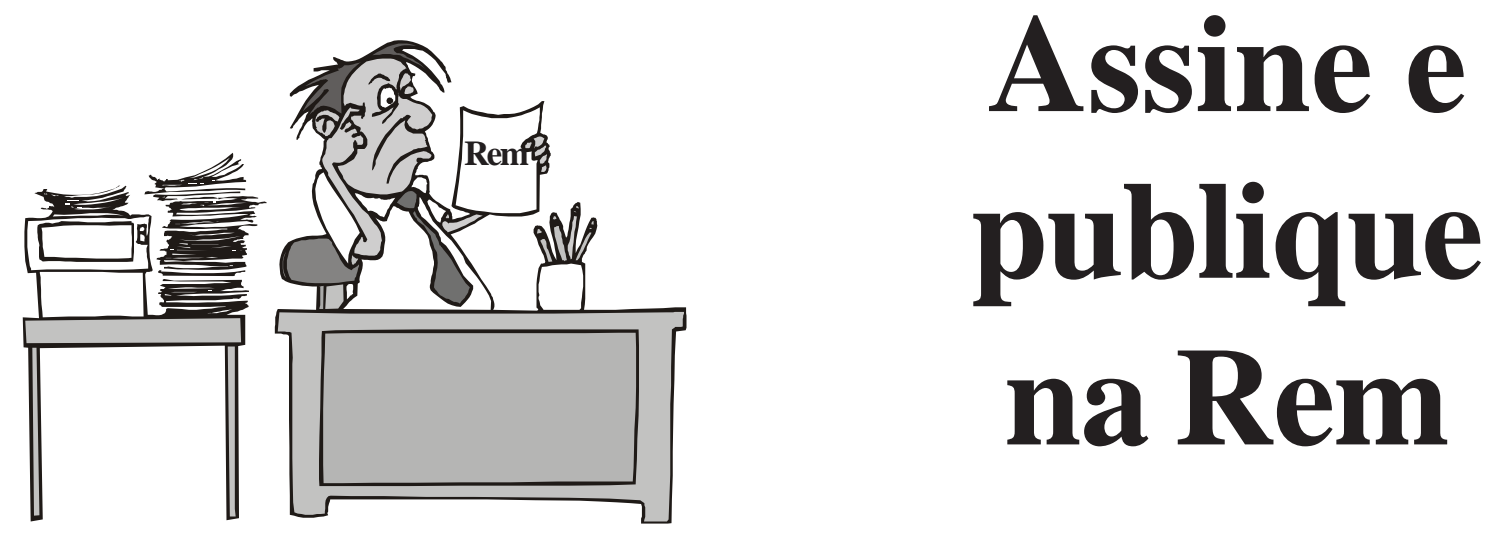

Conheça o nosso novo site: WWW.rem.com.br 